\title{
A Study of the Relationship among Self-efficacy, Help-Seeking Behaviors and Intention of Continue Participation in the "Insect Feeding Game"
}

\author{
Chin-Chieh Juh, Chow-Chin Lu, and Jon-Chao Hong
}

\begin{abstract}
In Taiwan, the 12-year compulsory education was implemented in 2019. The nature curriculum emphasizing the importance of students' self-learning and problem-solving skills. This study applied an "insect breeding game" to understand the relationship of students' participation in self-efficacy, help-seeking behavior, and intention of continue participation in the game. In this study, 206 students of the 4th grade primary students participated. This study adopted a method of questionnaire survey, Through a valid and reliable questionnaire (Cronbach's $\alpha=0.879$ ), Path analysis of data from 206 effective responses was performed using SPSS (version 22) and structural equation modeling-AMOS (version 21). The conclusions were: 1 . the game's self-efficacy of student was significantly positively correlated with instrumental help-seeking behavior. 2. There was no significant correlation between game's self-efficacy and executive help-seeking behavior. 3. Instrumental help-seeking behavior was significantly positively correlated with the intention of continue participation. 4. Executive help-seeking behavior was significantly positively correlated with the intention of continue participation. The suggestions of this study enabled educators to focus on the self-efficacy of students' participation in game-based-eLearning and encouraged students' help-seeking behaviors to enhance their intention to continue participate in game-based- eLearning on future.
\end{abstract}

Index Terms - Self-efficacy, help-seeking behavior, intention of continue participation, insect feeding game.

\section{INTRODUCTION}

In Taiwan, the 12-year compulsory education was implemented in 2019. The nature curriculum focuses on inquiry and implementation. According to the observations of educators in the past 10 years, it was found that the use of interesting games was an educational strategy full of opportunities [1], [2]. Many evidences also shows that digital game assisted instruction can have better learning outcomes than traditional teaching [3]. [4] the cognitive learning theory of multimedia learning (Cognitive- Affective theory of learning with media, CATLM), multimedia affects the effectiveness of learning methods and enhances cognitive and emotional processes." Learning in the game" can increase student's curiosity [5], experience fun, Improve game self-efficacy [6]. Previous studies have found that

Manuscript received August 25, 2019; revised March 14, 2020.

Chin-Chieh Juh and Chow-Chin Lu are with the Department of Science Education, National Taipei University of Education, Taiwan (e-mail: jackjuh@tp.edu.tw, luchowch@tea.ntue.edu.tw).

Jon-Chao Hong is with the Department of Industrial Education, National Taiwan Normal University, Taiwan (e-mail: tcdahong@gmail.com). digital games cuold make learning more active [7], and the study also showed that computer game characters can be used to improve learning enthusiasm and persistence. Enable learners to gain knowledge and practice in different educational games [8].

Due to the wide variety of insects in Taiwan, it is an excellent teaching resource and is very suitable for primary students [9]. However, in the nature science curriculum of elementary school in Taiwan, it is inconvenient to guide the understanding of insect structure and related knowledge to seasonal or local factors. It is inconvenient to search for real life insects in the classroom [10], [11], so it is suitable for teaching with insect games.

In terms of motivational traits, self-efficacy is one of the most important factor of educational outcomes [12]. Self-efficacy is a key factor in self-confidence, learning behavior, learning outcomes, and learning environment [13]. Therefore, this study was explored the relationship among self-efficacy and learning behavior in insect feeding game.

Help-seeking is one of the learning behaviors in the social learning theory. The help-seeking behavior refers to the learner's oral or non-verbal help to teachers, classmates or other subjects when they encounter difficulties and obstacles in the coursework, in order to solve the problem smoothly and complete the study [14]. Nelson-Le Gall is divided into executive help-seeking and instrumental help-seeking according to the motivation.

Motivation is an important factor in facilitating and sustaining behavior. Challenges, curiosity and social interactions influence the player's intention to continue to participate in online games [15]. From the help-seeking behavior, students can gain a sense of accomplishment from the game clearance process, to affirm their ability and increase their self-confidence, and have a direct impact on the continued play of game intentions [16].

Based on the above literature review, this study attempts to explore the correlation between self-efficacy, executive help, instrumental help and ongoing participation in insect feeding games to determine the effectiveness of this game in the development of affection. The game is suitable for the primary school children to learn. It is expected that this game will enhance students' interest in learning, increase learning efficiency, and apply the skills learned in the game to actual life, and maintain the motivation for continuous learning. This will provide research results to future researchers and educators to incorporate digital games into the educational environment, as well as provide appropriate suggestions for improving future teaching software design and enhancing 
teaching effectiveness.

\section{INSECT FEEDING GAME}

The insect feeding game APP was developed by the team of professor Hong at National Taiwan Normal University. It was developed for elementary school students and research situations. There are four different insect feeding tasks in the game design. After entering the game, students must follow the insect breeding needs. Conditions for the game, including food, growing environment and natural enemies and other factors affecting growth, until all growth conditions are in line to allow insects to grow up smoothly, and there is no restriction on the type and number of insects to be kept, students are free to choose the game task.

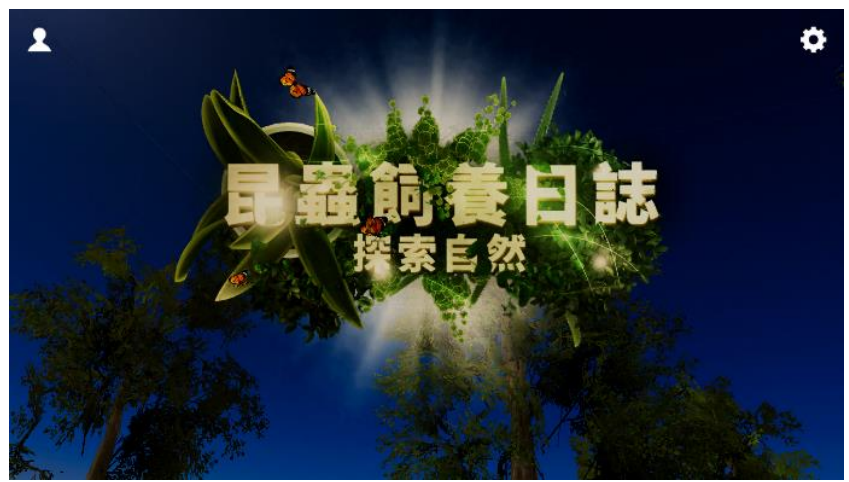

Fig. 1. Logo page for insect feeding game.

\section{A. The Game Operation and Rules}

1) Each student registers their own account number in order to manage the growth of the insects they keep.

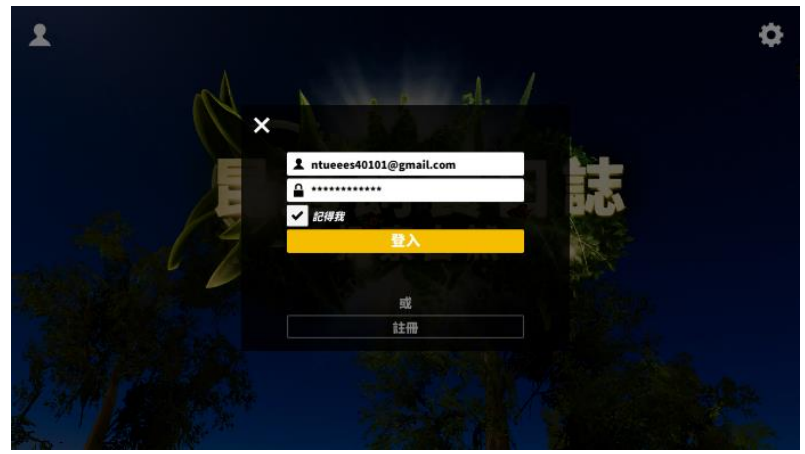

Fig. 2. Registers account number.

2) Enter the operating instructions to understand how to choose insects, find food, solve insect troubles and be careful with natural enemies.

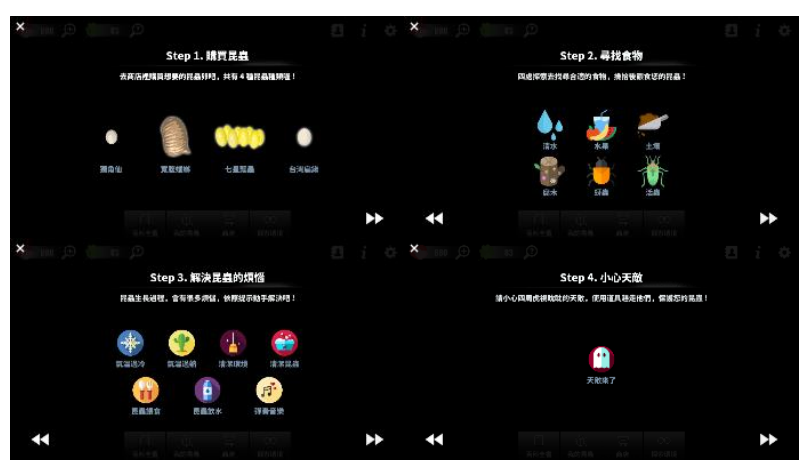

Fig. 3. Insect feeding game operating instructions.
3) In order to increase the chances of successful student breeding, provide information on insects such as cockroaches, unicorns, cockroaches and ladybugs, including characteristics, life, food, natural enemies and living environment.

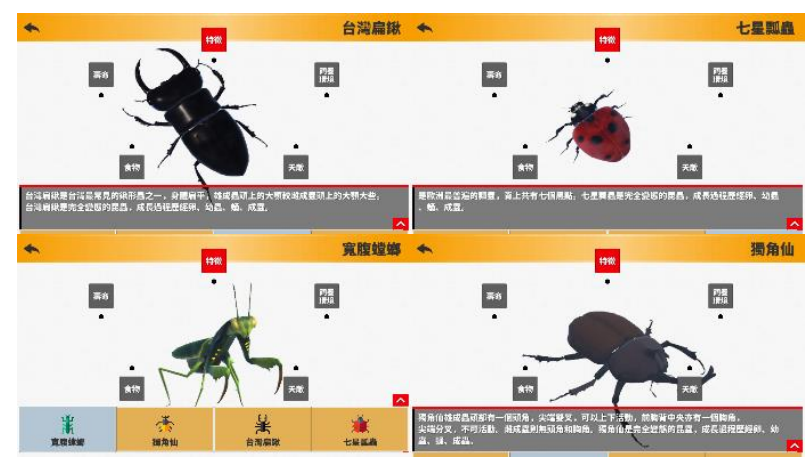

Fig. 4. Insect encyclopedia.

4) Provides a visualized interface, the left side is responsible for controlling the direction of move, and the right side provides options for smashing treasures, repelling natural enemies, and jumping.

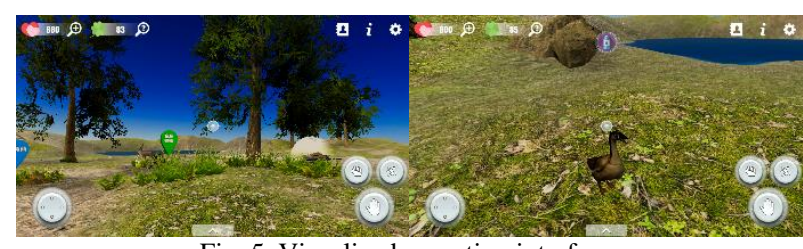

Fig. 5. Visualized operating interface.

5) During the game, the situation of real breeding insects will be simulated. If problems occur, ask the students to solve the problem in time, otherwise the insects will die or be eaten by natural enemies.

\section{B. Insect Growth Conditions}

The main growth conditions in the game are divided into three parts: food, environment and natural enemies. Different insects may have different growth conditions. The items needed for food and environment can be picked up in the game and coins can be obtained at the same time. Buy the tools you need at the store to increase the fun of the game, or when the insects die, you can buy eggs and restart.

1) Different insects have different food conditions (see Table I).

TABLE I: FOOD CONDITIONS

\begin{tabular}{lllll}
\hline \hline & $\begin{array}{l}\text { praying } \\
\text { mantis }\end{array}$ & $\begin{array}{l}\text { rhinoceros } \\
\text { beetle }\end{array}$ & $\begin{array}{l}\text { Stag } \\
\text { beetle }\end{array}$ & ladybug \\
& $\checkmark$ & $\checkmark$ & $\checkmark$ & $\checkmark$ \\
water & & $\checkmark$ & $\checkmark$ & \\
fruit & & $\checkmark$ & $\checkmark$ & \\
soil & & $\checkmark$ & $\checkmark$ & \\
Offal-timber & & & & $\checkmark$ \\
aphids & & & & $\checkmark$ \\
insect & $\checkmark$ & & \\
\hline \hline
\end{tabular}

2) In the game, insects will have many troubles. When it happens, the game will remind the students and ask the students to solve the problem according to the instructions:

1) The ambient temperature is too high or too low.

2) The living environment is messy and needs to be cleaned.

3) The insect body needs to be cleaned. 
4) need to feed food

5) need to feed water

6) Let the insects play the music, this is to add the added function of fun.

\section{Methodology}

\section{A. Research Mode}

Based on the purpose of the study, this study used insect feeding games to investigate and collect relevant data using questionnaires to understand the relevance of game self-efficacy, executive help-seeking behavior, instrumental help-seeking behavior, and Intention of continue participation. Before the insect feeding game, the students were informed of the purpose of the learning and the rules of the game, and the game was played for 40 minutes in the classroom. After the game was completed, the students were required to complete the questionnaire to collect student data and analysis data with SPSS and AMOS. The processing and to explore the relationship of each dimension.

\section{B. Research Design}

1) Research objects and data collection

The study participants were 4th grade of students in Taipei. In this study, each student could use a tablet to carry out insect feeding games. During the game, students could discuss or cooperate with other students to complete the game. In the course of the experiment, the researchers encouraged students to find ways to solve problems and play the game. A total of 206 valid questionnaires were collected in this study.

2) Preparing the questionnaire

The content of this questionnaire was based on the previous research questionnaire and had been revised. It was divided into self-efficacy, executive help-seeking behavior, instrumental help-seeking behavior and Intention of continue participation. The item of each dimension was verified with confirmatory factor analysis (CFA) and the Likert five-point scale was used to calculate the scores. Scored from 1 to 5 points.

\section{RESULT}

This study was based on three steps to analysis data. The order was reliability and validity analysis, test of goodness-of-fit and Path analysis.

\section{A. Reliability and Validity Analysis}

1) The composite reliability (CR) test of the construct was used to determine the consistency of the questionnaire [17]. All CR values in this study ranged from 0.91 to 0.94 , exceeding the recommended value of 0.80 [18], all values were consistent with acceptable composite reliability.

2) In order to evaluate internal consistency, the internal reliability of the questionnaire was examined using Cronbach's $\alpha$. The $\alpha$ values of each dimension ranged from 0.90 to 0.93 , and all values of $\alpha$ were greater than 0.8 , while the $\alpha$ values of the questionnaire was 0.879 [19], [20] all suggested that $\alpha$ values were more than 0.8.there were high confidence levels.

3) Verification validity of this study, the average variance extracted (AVE) of each dimension were between $0.72-0.74,[17],[21]$ recommended that the value of AVE should preferably more than 0.50 .

4) Table II shows that all values meet all necessary conditions [22], indicates that the construct validity of the questionnaire was acceptable.

TABLE II: CONFIRMATORY ANALYSIS (CONVERGENCE VALIDITY AND COMBINATION RELIABILITY)

\begin{tabular}{llllll}
\multicolumn{7}{c}{ COMBINATION RELIABILITY) } \\
\hline \hline Dimension & $\mathrm{M}$ & $\mathrm{SD}$ & Cronbach's $\alpha$ & $\mathrm{CR}$ & $\mathrm{AVE}$ \\
\hline Self-efficacy & 3.63 & 1.19 & 0.92 & 0.91 & 0.72 \\
$\begin{array}{l}\text { Executive } \\
\text { help-seeking } \\
\text { behavior }\end{array}$ & 3.25 & 1.07 & 0.90 & 0.93 & 0.77 \\
$\begin{array}{l}\text { Instrumental } \\
\text { help-seeking } \\
\text { behavior }\end{array}$ & 3.88 & 0.99 & 0.93 & 0.91 & 0.72 \\
$\begin{array}{l}\text { Intention of continue } \\
\text { participation }\end{array}$ & 3.77 & 1.10 & 0.93 & & \\
\hline \hline
\end{tabular}

\section{B. Test of Goodness-of-Fit}

Through the statistical analysis of the Structural Equation Modelling(SEM), the model fit index was shown in Table III. The $\mathrm{x}^{2} / d f$ is 2.40 , less than 5; RMSEA is 0.092 , less than 0.1 ; GFI and AGFI are 0.865 and 0.817 , respectively greater than 0.8 ; NFI is 0.913 , TLI was 0.936 , CFI was 0.947 , IFI was 0.947 , and each value was more than 0.9 , on the whole, the above indicators of the verification values were conformed to standard, showing that the SEM had a good model fit.

\begin{tabular}{ccc}
\multicolumn{3}{c}{ TABLE III: MODEL FIT INDEX } \\
\hline \hline INDEX & STANDARD & VERIFICATION VALUE \\
\hline $\mathrm{X}^{2}$ & & 240.49 \\
$d f$ & & 100 \\
$\mathrm{X}^{2} / d f$ & $<5$ & 2.40 \\
GFI & $>0.80$ & 0.865 \\
AGFI & $>0.80$ & 0.817 \\
RMSEA & $<0.1$ & 0.092 \\
NFI & $>0.90$ & 0.913 \\
TLI & $>0.90$ & 0.936 \\
CFI & $>0.90$ & 0.947 \\
IFI & $>0.90$ & 0.947 \\
\hline \hline
\end{tabular}

\section{Path Analysis}

Through the structural model, the path coefficients between the dimensions were analyzed to understand whether the data collected by the empirical study was adapted to the theoretical deduction mode, and then the research hypothesis is verified. After the AMOS statistical software analysis, the path diagram of the hypothetical model path was drawn., as shown in Fig. 6.

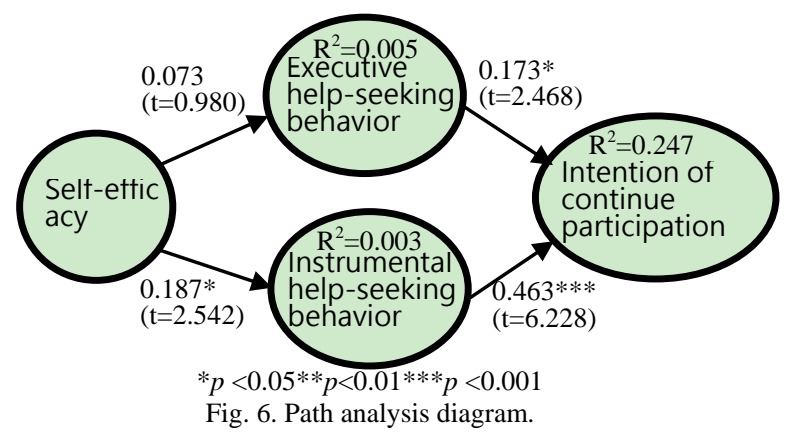


This research model had a total of four sets of hypothetical paths. There was no relationship between self-efficacy and executive help-seeking behavior, and the relationship between the other dimensions were statistically significant level.

\section{DisCUSSION}

Many studies had shown that self-efficacy and help-seeking behaviors had significant predictive effects. The results were consistent with this study, but this study divided the help-seeking behavior into instrumentality and execution, and found that self-efficacy was only related to instrumental help-seeking behavior. Described in social learning theory, when self-efficacy would be improved, it was confidence to encountered problems and solved problems.

In game-base-eLearning environment helped to improve students' learning motivation, but did not mean that they would continue to participate in learning. This study showed that help-seeking behavior could affect students' intention to continue participate. From the theory of social cognitive learning, the behavior was influenced by people and environment. When problems were solved in game, the self-efficacy would be improved and the intention to continue participate would be generated. Therefore, in the process of game learning, the problem was solved through help-seeking behavior. After the achievement, the intention to continue participate could be enhanced.

\section{CONCLUSION AND SUGGESTION}

The conclusions of this study were:

1) The game's self-efficacy of student was significantly positively correlated with instrumental help-seeking behavior.

2) There was no significant correlation between game's self-efficacy and executive help-seeking behavior.

3) Instrumental help-seeking behavior was significantly positively correlated with the intention of continue participation.

4) Executive help-seeking behavior was significantly positively correlated with the intention of continue participation.

The suggestions of this study for educators were:

1) Focus on improving the self-efficacy of students' in game-based-eLearning that could enhance students' instrumental help-seeking behaviors if they had problem in game.

2) Encouraged students' help-seeking behaviors to enhance their intention to continue participate in game-basedeLearning on future.

\section{CONFLICT OF INTEREST}

The authors declare no conflict of interest.

\section{AUTHOR CONTRIBUTIONS}

Juh conducted the research; Juh and Hong analyzed the data; Juh and Lu wrote the paper; all authors had approved the final version.

\section{REFERENCES}

[1] T. M. Connolly, E. A. Boyle, E. MacArthur, T. Hainey, and J. M. Boyle, "A systematic literature review of empirical evidence on computer games and serious games," Computers \& Education, vol. 59, no. 2, pp. 661-686, 2012.

[2] C. Steinkuehler, K. Squire, and S. Barab, Games, Learning, and Society: Learning and Meaning in the Digital Age, Cambridge, UK: Cambridge University Press, 2012.

[3] J. M. Laffey, L. Espinosa, J. Moore, and A. Lodree, "Supporting learning and behavior of at-risk young children: Computers in urban education," Journal of Research on Technology in Education, vol. 35, no. 4, pp. 423-440, 2003

[4] R. Moreno, "Does the modality principle hold for different media? A test of the methodaffects-learning hypothesis," Journal of Computer Assisted Learning, vol. 22, no. 3, pp. 149-158, 2006.

[5] J. Webster, L. K. Trevino, and, L. Ryan, "The dimensionality and correlates of flow in human-computer interactions," Computers in Human Behavior, vol. 9, no. 4, pp. 411-426, 1993.

[6] D. Potosky, "A field study of computer efficacy beliefs as an outcome of training: The role of computer playfulness, computer knowledge, and performance during training," Computers in Human Behavior, vol. 18,no. 3, pp. 241-255, 2002.

[7] C. L. Selfe, G. E. Hawisher, D. V. Ittersum, and J. P. Gee, Gaming Lives in the Twenty-First Century, New York, NY: Palgrave Macmillan, 2016.

[8] J. J. Vogel, D. S. Vogel, J. Cannon-Bowers, C. A. Bowers, K. Muse, and M. Wright, "Computer gaming and interactive simulations for learning: A meta-analysis," Journal of Educational Computing Research, vol. 34, no. 3, pp. 229-243, 2006.

[9] Y. C. Chen and G. Z. Liao, "Investigation on materials design of virtual reality and ARCS for understanding insects," Journal on Digital Learning Technology, vol. 5, no. 1, pp. 51-68, Jan. 2013.

[10] C. C. Lu and H. C. Shih, "Playing "insects playing board games" to cultivate the scientific process skills of primary school students," Chinese Journal of Science Education, vol. 24, no. 1, pp. 1-30, 2016.

[11] M. C. Lee and H. Y. Chen, "Thematic teaching of infusion the insect teaching into life education for children," Journal of Teaching Practice and Pedagogical Innovation, vol. 52, no. 5, pp. 72-80, Jun. 2012.

[12] M. Jansen, R. Scherer, and U. Schroeders, "Students' self-concept and self-efficacy in the sciences: Differential relations to antecedents and educational outcomes," Contemporary Educational Psychology, vol. 41, pp. 13-24, 2015

[13] L. Stankov, J. Lee, W. Luo, and D. J. Hogan, "Confidence: A better predictor of academic achievement than self-efficacy, self-concept and anxiety?" Learning and Individual Differences, vol. 22, no. 6, pp. 747-758, 2012.

[14] N. L. Gall," Help-seeking: An understudied problem-solving skill in children," Developmental Review, vol. 1, pp. 224-246, 1981.

[15] F. D. Davis, R. P. Bagozzi, and P. R. Warshaw, "Extrinsic and intrinsic motivation to use computers in the workplace," Journal of Applied Social Psychology, vol. 22, No. 14, pp. 1111-1132, 1992.

[16] T. W. Malone and M. R. Lepper, "Making learning fun: A taxonomy of intrinsic motivations of learning," Aptitude, Learning, and Instruction: Conative and Affective Process Analyses, vol. 3, pp. 223-253, 1987

[17] C. Fornell and D. F. Larcker, "Evaluating structural equation models with unobservable variables and measurement error," Journal of Marketing Research, vol. 18, no. 1, pp. 39-50, 1981.

[18] J. F. Hair, W. C. Black, B. J. Babin, and R. E. Anderson, Multivariate Data Analysis, 7th ed. Upper Saddle River, NJ: Pearson Prentice Hall, 2009.

[19] J. F. Hair, G. T. M. Hult, C. M. Ringle, and M. Sarstedt, A Primer on Partial Least Squares Structural Equation Modeling, Thousand Oaks, CA: Sage, 2013.

[20] G. R. Hancock and R. O. Mueller, Structural Equation Modeling: A Second Course, 2nd ed. Charlotte, NC: Information Age, 2013.

[21] R. P. Bagozzi and Y. Yi, "On the evaluation of structural equation models," Journal of the Academy of Marketing Science, vol. 16, no. 1, pp. 74-94, 1988.

[22] B. M. Byrne, Structural Equation Modeling with AMOS: Basic Concepts, Applications, and Programming, 3rd ed. London, UK: Routledge, 2016.

Copyright (C) 2020 by the authors. This is an open access article distributed under the Creative Commons Attribution License which permits unrestricted 
use, distribution, and reproduction in any medium, provided the original work is properly cited (CC BY 4.0).

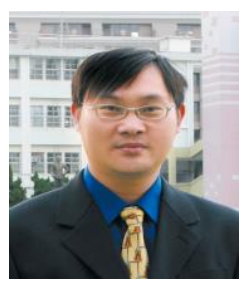

Juh Chin-Chieh is doctoral student that studies in the Department of Science Education, National Taipei University of Education, Taiwan. To study nature curriculum that focuses on inquiry and implementation, emphasizing the importance of students' self-learning and problem-solving skills.

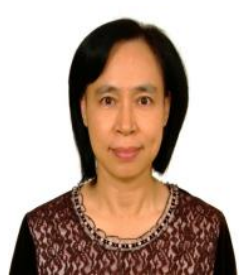

Lu Chow-Chin received the Ph.D. degree in zoology from National Taiwan University, Taipei, Taiwan, in 1994. Chow-Chin $\mathrm{Lu}$ is a professor working at the Department of Science Education, National Taipei University of Education, Taiwan. Her research interest has been focused on curriculum and instruction development, Biological concept research, elementary school teacher training, and science textbook research. She has over 100 papers published in the journals or presented in the conferences. Major journals that her papers published include Journal of Mathematics Science and Technology Education (SSCI), Learning and Individual Differences (SSCI), Thinking Skills and Creativity (SSCI), International Journal of Science and Mathematics Education (SSCI) and Asia-Pacific Forum on Science Learning and Teaching. Her research interests are focusing on three major areas: (1) Elementary school teacher training, teaching strategy mechanism and change process of teacher believes.
(2) Inquiry teaching and implementation including STEM, STEAM curriculum design. (3) Bio-bionics curriculum design and teaching.

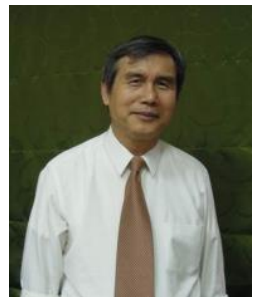

Hong Jon-Chao has received his doctoral degree in education from the University of Illinois, Champaign-Urbana, and is currently working as a chair professor in the Department of Industrial Education at National Taiwan Normal University (NTNU). As the director of Digital Game-Based Learning Laboratory (GBL), he has developed 9 web games, 24 educational Apps and VR for skill training and language learning.

As the secretary general of Taiwan Creativity Development Association, he also organizes several creative contests relevant to STEAM, such as PowerTech Contest to invite elementary, junior and senior high school students to produce robots or miniatures in the morning and using these to compete in the afternoon to ensure students' hands-on creation without parents or teachers' assistance. As the executive secretary of International Exhibition for Young Inventors (IEYI), he also promotes the innovative contest to give students an opportunity to stimulate their science inquiry abilities, and also cultivated students' creativity and thinking attitude of STEAM. In addition, he has published a number of academic articles in international journals related to digital game-based learning and thinking skills and creativity about 45 articles on Social Sciences Citation Index(SSCI) journals and received the Outstanding Research Prize from Ministry of Science and Technology in Taiwan. 